\title{
Eficácia de resíduos da bananicultura sobre a inibição do desenvolvimento larval em Haemonchus spp. provenientes de ovinos
}

\author{
Efficacy of banana crop residues on the inhibition of larval development in Haemonchus spp. \\ from sheep
}

\author{
Lincoln Nunes Oliveira ${ }^{\mathrm{I}}$ Eduardo Robson Duarte ${ }^{\mathrm{I}^{*}}$ Flávia Aparecida Nogueira $^{\mathrm{I}}$ \\ Rayana Brito da Silva ${ }^{\mathrm{I}}$ Daniel Emygdio de Faria Filho" ${ }^{\mathrm{II}}$ Luciana Castro Geraseev $^{\mathrm{II}}$
}

\section{- NOTA -}

\section{RESUMO}

Com o presente estudo, foi avaliada a eficácia in vitro de extratos vegetais de resíduos da bananicultura sobre a inibição do desenvolvimento larval de nematódeos gastrintestinais de ovinos. A técnica de coprocultura quantitativa e qualitativa foi empregada para avaliar a eficácia anti-helmíntica dos extratos aquosos de folhas, pseudocaules e corações de bananeiras da cultivar 'Prata Anã', nas concentrações 25, 75 e $150 \mathrm{mg} \mathrm{mL}^{-1}$, em um delineamento inteiramente casualizado. Os resultados obtidos demonstraram que os três extratos, em concentrações iguais ou superiores a $75 \mathrm{mg}^{\mathrm{m} \mathrm{L}^{-1}}$, reduziram significativamente $(P<0,05)$ o desenvolvimento larval dos nematódeos, com eficácia acima de 96,9\%. A identificação das larvas desenvolvidas revelou a ocorrência de Haemonchus spp. nas culturas avaliadas, permitindo concluir que as partes testadas da bananeira apresentam propriedades anti-helmínticas sobre o desenvolvimento larval desse importante parasito.

Palavras-chave: ovinos, Haemonchus spp., fitoterápicos, coprocultura, Musa spp.

\section{ABSTRACT}

This study evaluated the in vitro efficacy of aqueous extracts from banana crop residues on the inhibition of larval development of sheep gastrointestinal nematodes. The quantitative and qualitative coproculture technique was performed to evaluate the anthelmintic efficacy of the aqueous extract of leafs , pseudostems and hearts from banana plants, $\mathrm{cV}$ 'Prata Anã', at 25, 75 and $150 \mathrm{mg} \mathrm{mL}^{-1}$ concentrations, in a completely randomized design. The results showed that the three extracts, in concentrations equal to or greater than $75 \mathrm{mg} \mathrm{mL} \mathrm{L}^{-1}$, decreased significantly $(P<0.05)$ the nematodes larval development, with efficacy up 96.9\%. The identification of the developed larvae revealed occurrence of Haemonchus spp. in the evaluated samples, allowing to conclude that the tested parts of this plant showed anthelmintic properties on the larval development of this important parasite.

Key words: sheep, Haemonchus spp., phytotherapic, coproculture, Musa spp.

O frequente tratamento da verminose ovina, exclusivamente com anti-helmínticos sintéticos, tem permitido a rápida seleção de populações de helmintos resistentes, inviabilizando a ovinocultura em diferentes regiões geográficas (FURTADO, 2006). Estudos promissores, objetivando o controle dos parasitos e a redução dos impactos da resistência, têm relacionado inúmeras espécies vegetais com propriedades antiparasitárias e, dentre várias, destaca-se a Musa spp., conhecida como bananeira (OLIVEIRA et al., 1997; BEZERRA et al., 2002; BATATINHA et al., 2004).

No entanto, resultados científicos que comprovam o grau e as espécies de nematódeos de ovinos sensíveis a essa planta são escassos (OLIVO et al., 2007). Sendo assim, no presente estudo, teve-se como objetivos avaliar e comparar a eficácia in vitro de extratos aquosos de diferentes partes de bananeiras sobre o desenvolvimento larval de nematódeos gastrintestinais de ovinos.

O estudo foi conduzido no laboratório de parasitologia do Instituto de Ciências Agrárias da Universidade Federal de Minas Gerais (ICA/UFMG),

ICurso de graduação em Zootecnia, Instituto de Ciências Agrárias (ICA), Universidade Federal de Minas Gerais (UFMG), Montes Claros, MG, Brasil.

IICA/UFMG, Av. Universitária, 1000, Bairro Universitário, 39400-006, Montes Claros, MG, Brasil. E-mail: duartevet@hotmail.com.

*Autor para correspondência. 
latitude $16^{\circ} 44^{\prime} 02.8^{\prime \prime}$ S e longitude $43^{\circ} 51^{\prime} 23.3^{\prime \prime}$ W. As coletas foram realizadas entre os meses de junho e agosto de 2008.

Três diferentes extratos vegetais foram produzidos, segundo a metodologia de extração aquosa a quente, proposta por FURTADO (2006). Para tanto, foram selecionadas aleatoriamente seis bananeiras 'Prata Anã’, espécie mais difundida comercialmente na região, provenientes do setor de fruticultura do ICA/UFMG. Foram coletados as folhas desenvolvidas, os dois terços superiores de pseudocaules na colheita dos cachos e os corações. No preparo dos extratos, foram selecionadas e utilizadas somente partes vegetais que não continham sinais de lesões ou deterioração.

O material vegetal selecionado foi cortado, seco em estufa com circulação forçada de ar a $40^{\circ} \mathrm{C}$, até atingir peso constante, e triturado em moinho de facas tipo Willey. Os extratos foram obtidos submergindo totalmente os fragmentos vegetais em água destilada. $\mathrm{O}$ material foi incubado em banho-maria a $60^{\circ} \mathrm{C}$, por 60 minutos. Após esse tempo, foi realizada filtração a quente em funil com algodão.

Os extratos obtidos foram concentrados em estufa com circulação forçada de ar a $40^{\circ} \mathrm{C}$, até atingir peso constante, sendo então denominados extratos brutos (EB). Amostras foram submetidas à determinação de matéria seca (MS), a $105^{\circ} \mathrm{C}$, para cálculo das concentrações a serem testadas.

Para a obtenção das fezes, foram utilizados dois ovinos machos da raça Santa Inês, com idade entre cinco e sete meses, infectados naturalmente, procedentes do setor de ovinocultura do ICA/UFMG. Esses e outros ovinos do setor apresentavam altas e persistentes infecções helmínticas, mesmo após três vermifugações consecutivas com diferentes princípios ativos.

As amostras de fezes foram coletadas diretamente da ampola retal, em duas coletas sucessivas no mesmo dia. Em seguida, foram transportadas em caixas isotérmicas ao laboratório de parasitologia do ICA/ UFMG, sendo imediatamente homogeneizadas e submetidas à determinação de ovos por grama de fezes (OPG) (GORDON \& WHITLOCK, 1939), revelando contaminação parasitária média de 3,7 mil ovos.

A eficácia de cada extrato sobre o desenvolvimento larval dos nematódeos foi avaliada nas concentrações 25 , 75 e $150 \mathrm{mg} \mathrm{mL}^{-1}$, comparando-se com controles negativos com água destilada estéril, em triplicata, de acordo com a metodologia descrita por BORGES(2003).

As parcelas experimentais contendo $2 \mathrm{~g}$ de fezes, $2 \mathrm{~g}$ de serragem e $2 \mathrm{~mL}$ do respectivo extrato diluído ou água destilada estéril, no caso do grupo controle, permaneceram incubadas durante sete dias, em estufa BOD, a $34^{\circ} \mathrm{C}$ e $85 \%$ de umidade. Posteriormente, as larvas desenvolvidas foram contadas e identificadas, conforme UENO\& GONÇALVES (1998).

O número total de larvas observado em cada parcela foi dividido por dois, sendo o resultado expresso em larvas desenvolvidas por grama de fezes (LDPG). O percentual de redução das LDPG (eficácia) pelos extratos foi determinado em comparação com o grupo controle a partir da seguinte fórmula: \% eficácia = [1 - (média de LDPG no grupo tratado / média de LDPG no grupo controle)] x 100.

Para a análise estatística, o número de LDPG em cada parcela sofreu transformação logarítmica, Log $(\mathrm{X}+10)$. Utilizou-se um delineamento inteiramente casualizado, em esquema fatorial $3 \mathrm{x} 3$, com os fatores extratos (folha, pseudocaule e coração) e concentrações (25, 75 e 150mg mL $\mathrm{m}^{-1}$ ), em triplicata. Os dados foram submetidos à análise variância, e as médias foram comparadas pelo teste de Tukey, a 5\% de significância, por meio do programa SAEG 9.1 (2007). Utilizando a análise de regressão Probit desse software, foram determinadas as doses dos extratos para inibir 50 (DL 50) e $90 \%$ (DL 90) do desenvolvimento larval.

Os controles apresentaram um número médio de 70,8 LDPG. Os três extratos não apresentaram diferenças significativas entre si, quando testados nas mesmas concentrações $(\mathrm{P}>0,05)$. No entanto, em concentrações iguais ou superiores a $75 \mathrm{mg} \mathrm{mL}^{-1}$, todos reduziram significativamente o desenvolvimento larval dos nematódeos $(\mathrm{P}<0,05)$, com eficácia média variando de 98,5 a $100 \%$, podendo, dessa forma, ser classificados como altamente efetivos, segundo WOOD et al. (1995).

As DL 50 e DL 90 para o extrato das folhas foram de 33,12 e 57,76 $\mathrm{mg} \mathrm{mL}^{-1}$, respectivamente, valores próximos aos encontrados para o extrato do pseudocaule, que apresentou DL 50 de $33,45 \mathrm{mg} \mathrm{mL}^{-1} \mathrm{e}$ DL 90 de 53,56mg mL $\mathrm{mL}^{-1}$. Não foi possível estimar os mesmos parâmetros para o extrato do coração das bananeiras, uma vez que este inibiu $100 \%$ do desenvolvimento larval em duas das três concentrações avaliadas, indicando que possa ter menores concentrações efetivas e uma possível superioridade em relação aos outros extratos.

Os resultados encontrados no presente estudo diferem daqueles obtidos por FURTADO et al. (2005), que testaram o extrato etanólico e o látex puro de flores de bananeira sobre a eclosão de larvas de nematódeos de ovinos e não observaram efeitos significativos. Entretanto, nos estudos conduzidos por BATATINHA et al. (2004), o extrato aquoso das folhas de bananeiras, avaliado em concentrações de 12,45 a 130,6mg $\mathrm{mL}^{-1}$ sobre o desenvolvimento larval de nematódeos de caprinos, inibiu até 97,9\% do desenvolvimento larval de Haemonchus spp. OLIVEIRA et al. (1997) também observaram redução in vivo de 57,1\% para Haemonchus spp. em caprinos alimentados com folhas de bananeiras durante 25 dias. 
BEZERRA et al. (2002), por sua vez, constataram uma redução na contagem de OPG em bovinos alimentados com folhas e pseudocaules da bananeira. De acordo com OLIVO et al. (2007), a atividade anti-helmíntica presente nas lâminas foliares da bananeira se deve possivelmente ao tanino encontrado em seus diversos cultivares.

No presente estudo, foi identificado que $100 \%$ das larvas desenvolvidas nas coproculturas dos grupos controle pertenciam ao gênero Haemonchus. Esse nematódeo, além de ser considerado um dos mais patogênicos para ovinos (VIEIRA, 2008), é o que apresenta maior prevalência nos rebanhos com relatos de resistência anti-helmíntica (MELO et al., 2003).

De acordo com FAROUK (2004), existem apenas cinco grupos de anti-helmínticos utilizados no controle de Haemonchus spp.. Para todos, têm sido observados relatos de resistência em diversos países, especialmente na América Latina (WALLER, 1999), o que torna relevante qualquer estudo que venha a contribuir no controle desse nematódeo.

Os resultados obtidos no presente estudo demonstram que os extratos aquosos das três partes da bananeira 'Prata Anã' avaliadas apresentam propriedades anti-helmínticas efetivas sobre o desenvolvimento larval de Haemonchus spp. No entanto, faz-se necessária a realização de testes in vivo, a fim de avaliar essas propriedades em condições naturais e possíveis efeitos tóxicos ou negativos no desempenho dos animais.

\section{AGRADECIMENTOS}

À Fundação de Amparo à Pesquisa do Estado de Minas Gerais - FAPEMIG, ao Fundo de Desenvolvimento Científico e Tecnológico - FUNDECI/Banco do Nordeste do Brasil e ao Instituto de Ciências Agrárias da Universidade Federal de Minas Gerais - ICA/UFMG.

\section{COMITÊ DE ÉTICA E BIOSSEGURANÇA}

Os procedimentos envolvendo animais foram realizados de acordo com os princípios éticos da experimentação animal, sendo aprovados pelo Comitê de Ética em Experimentação Animal da UFMG (protocolo 42/2008).

\section{REFERÊNCIAS}

BATATINHA, M.J.M. et al. Efeitos in vitro dos extratos de folhas de Musa cavendishii Linn. e de sementes de Carica papaya Linn. sobre culturas de larvas de nematóides gastrintestinais de caprinos. Revista Brasileira de Plantas Medicinais, v.07, p.11-15, 2004. Disponível em: <http://www.ibb.unesp.br/ servicos/publicacoes/rbpm/pdf_v ${ }_{-}$n1_2005/ artigo_3_v7_n1.pdf>. Acesso em: 17 out. 2008.

BEZERRA, L.J.D. et al. Estudo bromatológico da bananeira (Musa spp.) e sua utilização na alimentação de bovinos. Agronline, 2002. Disponível em: <http://www.agronline.com.br/ agrociencia/artigo/37>. Acesso em: 18 set. 2008.
BORGES, C.C.L. Atividade in vitro de anti-helmínticos sobre larvas infectantes de nematóides gastrintestinais de caprinos, utilizando a técnica de coprocultura quantitativa (Ueno, 1995). Parasitologia Latinoamericana, v.58, p.142-147, 2003. Disponível em: <http://www.scielo.cl/pdf/parasitol/v58n3-4/ art10.pdf>. Acesso em: 15 jun. 2008.

FAROUK, Z. Parasitismo em pequenos ruminantes. Bahia Agrícola, v.6, p.17-19, 2004. Disponível em: <http://www.seagri.ba.gov.br/pdf/ v6n3_6Parasitismo.pdf $>$. Acesso em: 19 jun. 2008.

FURTADO, S.K. Alternativas fitoterápicas para o controle da verminose ovina no estado do Paraná: testes in vitro e in vivo. 2006. 147f. Tese (Doutorado em Agronomia) - Curso de Pós-graduação em Agronomia, Universidade Federal do Paraná, Curitiba, PR.

FURTADO, S.K. et al. Efeito de Carica papaya L. (caricaceae) e Musa paradisiaca linn. (musaceae) sobre o desenvolvimento de ovos de nematóides gastrintestinais de ovinos. Arquivos do Instituto Biológico, v.72, p.191-197, 2005. Disponível em: < http://www.biologico.sp.gov.br/docs/arq/V72_2/furtado.PDF>. Acesso em 08 abr. 2009.

GORDON, H.M.; WHITLOCK, H.V. A new technique for courting nematode eggs in sheep faeces. Journal of Council of Science and Industry Research in Australia, v.12, p.50-52, 1939.

MELO, A.C.F.L. et al. Nematódeos resistentes a anti-helmínticos em rebanhos de ovinos e caprinos no estado do Ceará, Brasil. Ciência Rural, v.33, n.2, p.339-344, 2003. Disponível em: < http://www.scielo.br/pdf/\%0D/cr/v33n2/15226.pdf >. Acesso em 08 abr. 2009.

OLIVEIRA, D.B. et al. Atividade anti-helmíntica da bananeira (Musa spp.) em caprinos. In: CONGRESSO BRASILEIRO DE PARASITOLOGIA, 15., 1997, Salvador, BA. Anais... Salvador: Sociedade Brasileira de Parasitologia, 1997. p.65.

OLIVO, C.J. et al. Uso da bananeira (Musa spp.) no controle de parasitas de animais domésticos: do empirismo à ciência. Livestock Research for Rural Development, v.19, 2007. Disponível em: <http://www.lrrd.org/lrrd19/11/oliv19158.htm>. Acesso em: 18 out. 2008.

SAEG - Sistema para Análises Estatísticas, Versão 9.1: Fundação Arthur Bernardes. Viçosa: UFV, 2007. p. 301.

UENO, H; GONÇALVES, P.C. Manual para diagnóstico das helmintoses de ruminantes. 4.ed. Salvador: Japan Internatinal Cooperation Agency, 1998. 145p.

WALLER, P.J. International approaches to the concept of integrated control of nematode parasites of livestock. International Journal for Parasitology, v.29, p.155-164, 1999. Disponível em: <http://www.sciencedirect.com>. Acesso em: 23 out. 2008. doi: 10.1016/S0020-7519(98)00178-7.

WOOD, et al. World Association for the Advancement of Veterinary Parasitology (W.A.A.V. P.) second edition of guidelines for evaluating the efficacy of anthelmintics in ruminants (bovine, ovine, caprine). Veterinary Parasitology, v.58, p.181-213, 1995. Disponível em: <http://www.sciencedirect.com>. Acesso em: 23 out. 2008. doi: 10.1016/0304-4017(95)00806-2.

VIEIRA, L.S. Métodos alternativos de controle de nematóides gastrintestinais em caprinos e ovinos. Tecnologia \& Ciência Agropecuária, v.2, p.49-56, 2008. Disponível em: <http:// www.emepa.org.br/revista/volumes/tca_v2_n2_jun/ tca09_metodos.pdf>. Acesso em: 18 out. 2008. 